\title{
The development and maintenance of odor-based double-alternation responding under conditions of Thorazine and Elavil injection
}

\author{
STEPHEN F. DAVIS and ROGER L. THOMAS \\ Emporia State University, Emporia, Kansas 66801
}

and

\author{
ROBERT E. PRYTULA \\ Middle Tennessee State University, Murfreesboro, Tennessee 37132
}

\begin{abstract}
Two experiments investigating odor production and utilization in rats under the effects of Thorazine and Elavil injections, respectively, are reported. In Experiment 1, significantly slower speeds shown by the Thorazine-injected subjects indicated that this drug depressed performance. It is felt that depressed performance allowed these subjects to attend and respond to odor cues earlier in Phase 1 than did saline-injected control animals. Reversing the injection conditions (Phase 2) failed to disrupt already-established patterning. During the first phase of Experiment 2, Elavil-injected subjects failed to establish patterned responding, whereas such responding was readily established by saline-injected subjects. Reversing the injection conditions (Phase 2) resulted in the rapid development of double-alternation patterning by the subjects that were shifted from Elavil to saline and in the maintenance of such responding by the animals shifted from saline to Elavil.
\end{abstract}

For nearly a decade and a half, data pertaining to what has been called the "odor hypothesis" have been generated (e.g., Bloom \& Phillips, 1973; Eslinger \& Ludvigson, 1980; Ludvigson, 1969; Ludvigson \& Sytsma, 1967). This accumulating body of data has prompted several conclusions. For example, it appears that rat subjects exude either qualitatively and/or quantitatively different odors on reward (R) and nonreward $(\mathrm{N})$ occasions (Mellgren, Fouts, \& Martin, 1973) and, moreover, that such odors may be deprivation state dependent (Davis, Prytula, Harper, Tucker, Lewis, \& Flood, 1974; Davis, Prytula, Noble, \& Mollenhour, 1976; TravisNeideffer, Ludvigson, \& Moreno, Note 1). Performance on an eight-trial double-alternation schedule of reward/nonreward (i.e., RRNNRRNN) has frequently been used to ascertain such effects. When odors are maximized by administering the first trial to all subjects in a group before the second trial is run, and so forth through the eight-trial sequence, appropriate patterning (fast to reward, slow to nonreward) is strongly established after 8 or 9 days of

This research was supported by a Research and Creativity Grant from Emporia State University to the first author and by a faculty research grant from Middle Tennessee State University to the last author. training (Prytula \& Davis, 1974, 1976). Such data, in conjunction with T-maze studies (Morrison \& Ludvigson, 1970), indicate that odors, especially the odor of nonreward, can be established as discriminative stimuli controlling instrumental responding in subsequently tested animals.

Attempts have also been made to incorporate the production and utilization of such odors within a theoretical framework. One line of reasoning has attempted to link odor production with the arousal of frustration. The major assumption associated with this interpretation is that emotionally aroused or frustrated animals exude such odors and that nonfrustrated or emotionally blunted animals do not. In support of this position, Howard and $\mathrm{McHose}$ (1974) reported that nondrugged animals following odor-donor rats injected with sodium amobarbital failed to develop appropriate double-alternation patterning. Howard and McHose (1974) concluded "that the administration of sodium amobarbital prevented an emotional response to frustrative nonreward by the donor subjects and, consequently, these subjects provided no odor trails which could cue impending reward and nonreward events for the experimental subjects."

Likewise, Davis and Prytula (1979) reported a study in which groups of runway-trained animals 
were preceded by startbox-placed donors injected with chlorpromazine (Thorazine) or saline, respectively. The principal pharmacological actions of Thorazine are psychotropic. It has strong antiadrenergic, and weaker peripheral anticholinergic, effects. In humans, Thorazine is frequently used for the control or management of psychotic disorders (especially the manic type of manic-depressive illness) and for the relief of restlessness and apprehension prior to surgery. Strong patterning was developed in the start and run measures by subjects following startbox-placed donors injected with isotonic saline. Start- and run-measure patterning was not shown by animals following Thorazine-injected donors. It is interesting to note, however, that a reversal in the donor-injection condition failed to eliminate patterning in those subjects that had originally followed saline-injected donors. On the other hand, subjects that originally followed Thorazine-injected donors developed start- and run-measure patterning when the donors were shifted to saline.

Of potential importance is the fact that both the Davis and Prytula (1979) and Howard and McHose (1974) studies employed testing procedures under which odor cues exuded by drugged donors were to be used by subsequent nondrugged test animals. In view of the fact that odor cues appear to be drive state dependent (Davis et al., 1974, 1976; Travis-Neideffer et al., Note 1), it may be that the drug-induced state of the donors differed enough from that of the following test animals to render odor cues ineffective in some manner. Thus, patterning would not be predicted.

\section{EXPERIMENT 1}

Assuming the correctness of the drive-statedependency position, testing Thorazine-injected subjects as a homogeneous group might well result in the development of appropriate odor-based patterning. Under such conditions, odors produced by subjects tested under a specific drug state would be available and potentially utilizable by subsequent subjects tested under the same state. During the first phase of Experiment 1, one group of subjects received double-alternation runway training under the effects of a $2-\mathrm{mg} / \mathrm{kg}$ intraperitoneal (ip) injection of Thorazine, while a second (control) group received a similar injection of $.9 \%$ isotonic saline. In the second phase of the study, the injection conditions were reversed.

\section{Method}

Subjects. Fourteen male albino rats purchased from the Holtzman Company, Madison, Wisconsin, served as subjects. The subjects were approximately 90 days old at the beginning of experimental testing. All subjects were individually caged, with water available on a free-feeding basis. One week prior to the beginning of pretraining, all subjects were placed on a food- deprivation regimen that maintained them at $85 \%$ of their freefeeding body weights for the duration of the experiment.

Apparatus. The apparatus consisted of a single straight runway $(11.4 \mathrm{~cm}$ wide $\times 12.7 \mathrm{~cm}$ high) having a gray startbox $(28.1 \mathrm{~cm})$, black run section $(91.4 \mathrm{~cm})$, and black goalbox $(30.5 \mathrm{~cm})$. Masonite guillotine doors separated the startbox and goalbox from the run section. Start, run, and goal times, produced by the activation of a microswitch located on the start door and the interruption of a series of photoelectric cells (located 15.2, 92.4, and $116.8 \mathrm{~cm}$ beyond the start door) were recorded on all trials. A plastic receptacle recessed into the end wall of the goalbox served as the goal cup. A thin sheet of transparent plastic covered the top of the alley to prevent odors from dissipating.

Procedure. Prior to pretraining, two equal-sized $(n=7)$ groups, T-S and S-T, were formed randomly. Subjects within each group were assigned randomly a permanent running-order number (1-7).

A 4-day pretraining phase immediately preceded the experiment proper. Pretraining consisted of handling and taming (Days 1 and 2) and habituation to the 45-mg Noyes reward pellets in the home cage (Days 1-4). Each subject received a 5-min exploration period in the unbaited apparatus on Days 3 and 4.

All subjécts received eight daily trials in a double-alternation (RRNNRRNN) sequence during both phases of the experiment. To run a trial, the appropriate subject was removed from the home cage and placed in the startbox. Following a 10-sec confinement, the start door was raised and the subject was allowed to traverse the runway. Reward and nonreward events consisted of $1245-\mathrm{mg}$ pellets and a $30-\mathrm{sec}$ confinement to the empty goalbox, respectively. Subjects were tested in the same order (1-7) within respective groups on all days, with all daily trials being administered to a particular group before the next group was run. The order for running groups alternated daily. Before Trial 1 and after each subsequent trial for a group, the alley was thoroughly swabbed with a damp sponge and aired for $5 \mathrm{~min}$.

During Phase 1 (12 days, 96 trials) each subject in Group T-S received a daily $2-\mathrm{mg} / \mathrm{kg}$ ip injection of Thorazine $1 \mathrm{~h}$ prior to experimental testing, while each subject in Group S-T received a daily $2-\mathrm{mg} / \mathrm{kg}$ ip injection of $.9 \%$ isotonic saline prior to testing. During Phase 2 ( 8 days, 64 trials), the injection procedures were reversed (i.e., subjects in Group T-S were injected with saline and subjects in Group S-T were injected with Thorazine). Thus, the only difference between Groups T-S and S-T was the order of injection conditions.

\section{Results and Discussion}

Since the first animal in each group was always tested in a clean (swabbed and aired) runway, they served as "odor-donor" rats for subsequently tested animals. Hence, their data were not included in either statistical analyses or figures. Visual inspection of the speeds of these subjects indicated that they displayed nondifferential responding in all cases.

All latencies were reciprocated and multiplied by the appropriate constant to yield speed scores (meters/ sec). Prior to analysis and graphing, the speed scores for each daily eight-trial sequence were combined as follows: The first two trials were averaged to yield a composite $\left(\mathbf{R}_{1}\right)$ score, and so forth. Hence, daily double-alternation performance was reduced to four scores $\left(\mathbf{R}_{1}, \mathbf{N}_{1}, \mathbf{R}_{2}\right.$, and $\left.\mathbf{N}_{2}\right)$ for each subject. Mean goal speeds for Groups S-T and T-S for both phases of the experiment are shown in Figure 1.

Analyses of variance incorporating groups (T-S vs. S-T), double-alternation (DA) performance $\left(R_{1}, N_{1}\right.$, 


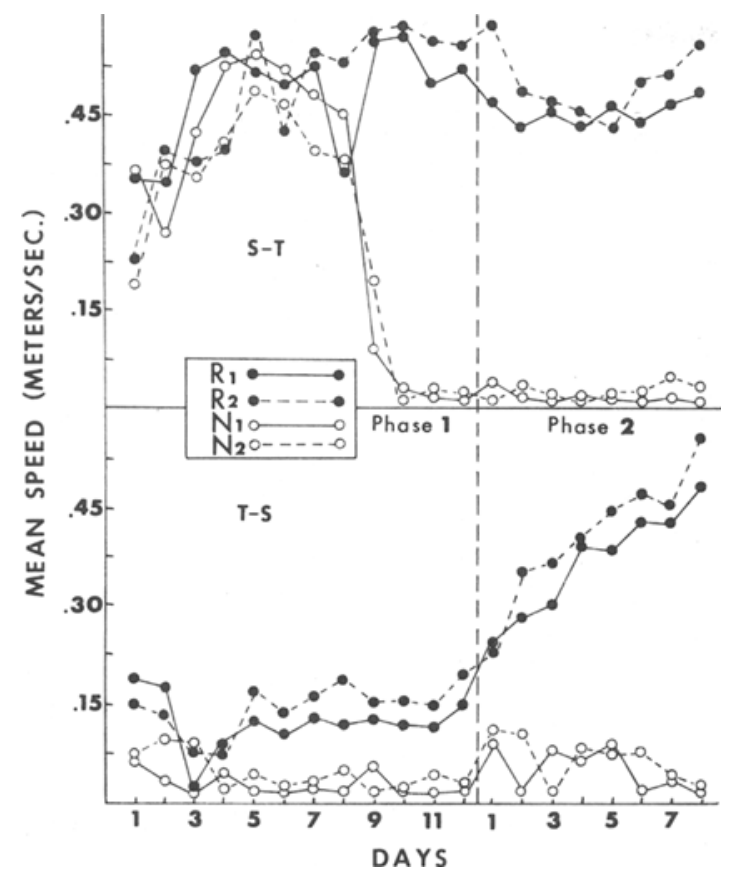

Figure 1. Mean goal speeds for Groups S-T and T-S during Phase 1 and 2 of Experiment 1.

$\mathbf{R}_{2}, \mathbf{N}_{2}$ ), and days factors were performed on the Phase 1 speed data from Days 5-12, the point at which patterning appeared to have been established by Group T-S. The Newman-Keuls procedure was employed to make specific comparisons in all cases. Group T-S speeds were found to be significantly slower than those of Group S-T in the start and run measures [start: $F(1,10)=9.14, p<.05$; run: $F(1,10)$ $=8.64, \mathrm{p}<.05]$. Goal-measure analysis yielded significance for the groups $[F(1,10=7.83, \mathrm{p}<.05]$, DA performance $[F(3,30)=6.39, p<.01]$, and groups $X$ DA performance $x$ days $[F(21,210)=2.03, p<.01]$ effects. Comparison tests indicated that from Days 5-8, all speeds of Group S-T were significantly $(\mathrm{p}<.01)$ faster than were all Group T-S speeds. From Days 9-12 both $R_{1}$ and $R_{2}$ speeds of Group $S-T$ were significantly $(p<.01)$ faster than all other speeds, and from Days 5-12 both $R$ speeds of Group T-S were found to be significantly $(p<.05)$ faster than both $\mathrm{N}$ speeds of this group.

Similar analyses were performed on the Phase 2 speeds. No significant effects were found in the start and run measures. Goal measure analysis yielded significance for the DA performance $[F(3,30)=18.52$, $\mathrm{p}<.01]$ and the groups $\times$ DA performance $\times$ days interaction $[F(7,210)=2.14, p<.05]$ effects. NewmanKeuls tests indicated that all $\mathrm{N}$ speeds were significantly (lowest $\mathrm{p}<.05$ ) slower than all $R$ speeds.

In accord with the initial prediction, the results of
Experiment 1 indicate that animals tested under the effects of Thorazine are capable of acquiring doublealternation patterning when odor conditions are made as homogeneous as possible. It is also worth noting that the Thorazine subjects (Group T-S) developed patterning earlier than did the saline subjects (Group S-T) in Phase 1 (Day 4 for Group T-S as compared with Day 9 for Group S-T). This finding, in conjunction with the depression in responding shown in all measures by Group T-S, suggests that the drug state may well have caused Group T-S subjects to attend to and respond to nonreward odors earlier in training than did subjects in Group S-T.

\section{EXPERIMENT 2}

If an adrenergic antagonist, such as Thorazine, has the effect of depressing performance and enhancing attention to odor cues, then it might be predicted that an adrenergic agonist, such as the tricyclic compound amitriptyline $\mathrm{HCl}$ (Elavil), might serve to potentiate performance and interfere with attentional processes. The principal pharmacological actions of Elavil are essentially opposite to those associated with Thorazine. Elavil inhibits the membrane pump responsible for the uptake of norepinephrine and serotonin in adrenergic and serotonin neurons. This action may potentiate or prolong neural activity, since reuptake of these biogenic amines is important in the termination of transmitting activity. In humans, Elavil is typically used for the relief of depression.

Data, supportive of the above prediction, have been reported by Davis, Whiteside, Dickson, Thomas, and Heck (1981). These investigators found that the display of defensive burying was depressed when subjects were tested under the effects of Thorazine. However, such behavior was potentiated when subjects were tested under the effects of Elavil.

The experimental design employed in Experiment 2 was essentially the same as that used in Experiment 1. During Phase 1, one group of subjects received daily eight-trial double-alternation training under the effects of Elavil, while a second group was trained under saline-injection conditions. However, unlike Experiment 1, all 14 animals were run as one large squad. During Phase 1 , the first seven subjects received Elavil injections, while the last seven subjects were injected with saline. Under this sequence, the first seven animals (Elavil injected) served as odor donors for the first subject in the saline sequence. It was hoped that an examination of the performance of this first saline subject would provide some indication of the discriminability of odors produced by the Elavil subjects. During Phase 2, the injection conditions were reversed for all subjects. 


\section{Method}

Subjects. Fourteen 90 -day-old male Holtzman rats served as subjects. The caging arrangements and deprivation procedures employed in Experiment 1 were also used in Experiment 2.

Apparatus. The straight runway used in Experiment 1 was also used in Experiment 2.

Procedure. Prior to pretraining, two groups of equal size $(n=7)$, E-S and S-E, were formed randomly. Subjects in each group were assigned randomly a permanent number (Group E-S, 1-7; Group S-E, 8-14). Pretraining procedures, similar to those in Experiment 1 , preceded experimental testing.

Subjects received the RRNNRRNN trial-administration sequence and were run in the 1-14 order on all days of the experiment. During Phase 1 (12 days, 96 trials), Subjects 1-7 (Group E-S) received a daily $2-\mathrm{mg} / \mathrm{kg}$ ip injection of Elavil $1 \mathrm{~h}$ prior to experimental testing, while Subjects 8-14 (Group S-E) received a daily $2-\mathrm{mg} / \mathrm{kg}$ ip injection of $.9 \%$ isotonic saline $1 \mathrm{~h}$ prior to testing. The injection conditions were reversed during Phase 2 (6 days, 48 trials). Thus, Elavil-injected subjects (Group E-S) immediately preceded saline-injected subjects (Group S-E) during Phase 1, but immediately followed such subjects during Phase 2. Trialadministration procedures, R- and N-Trial conditions, and swabbing/airing operations were similar to those employed in Experiment 1 .

\section{Results and Discussion}

The first animal in each group (i.e., Subjects 1 and 8) was not included in statistical analyses or graphs. Otherwise, reciprocation and data reduction procedures similar to those of Experiment 1 were also used in Experiment 2. Mean goal speeds for Groups S-E and E-S for both phases of Experiment 2 are shown in Figure 2.

Analyses, similar to those performed on the Experiment 1 data, were performed on the Phase 1 speeds of Days 7-12, the point at which appropriate goalmeasure responding appeared to have been established by Group S-E. Start- and run-measure analyses failed to yield significant effects. Goal-measure analysis yielded significant groups $[F(1,10)=6.55$, $\mathrm{p}<.05]$ and groups $\times$ DA performance $[\mathrm{F}(3,30)=$ $7.95, p<.01]$ effects. Subsequent comparisons indicated that the $\mathbf{R}$ speeds of Group S-E were significantly faster $(p<.01)$ than their $N$ speeds. Thus, the statistical analyses corroborate the graphical impression that appropriate Phase 1 patterning was shown only by Group S-E and that Group E-S approached the goal faster than did Group S-E.

Phase 2 analyses failed to yield any significant effects in the start and run measures. In the goal measure, significant DA performance $[F(3,30)=26.93$, $\mathrm{p}<.01]$ and groups $\times$ DA performance $\times$ days $[F(15,150)=1.87, p<.05]$ effects were found. In addition to showing general R-speed superiority $(p<.01)$, other specific comparisons indicated that Group E-S had developed significant $(p<.01)$ patterning by Day 2.

\section{GENERAL DISCUSSION}

The results of these two experiments indicate that runway performance of the rat is affected by injec-

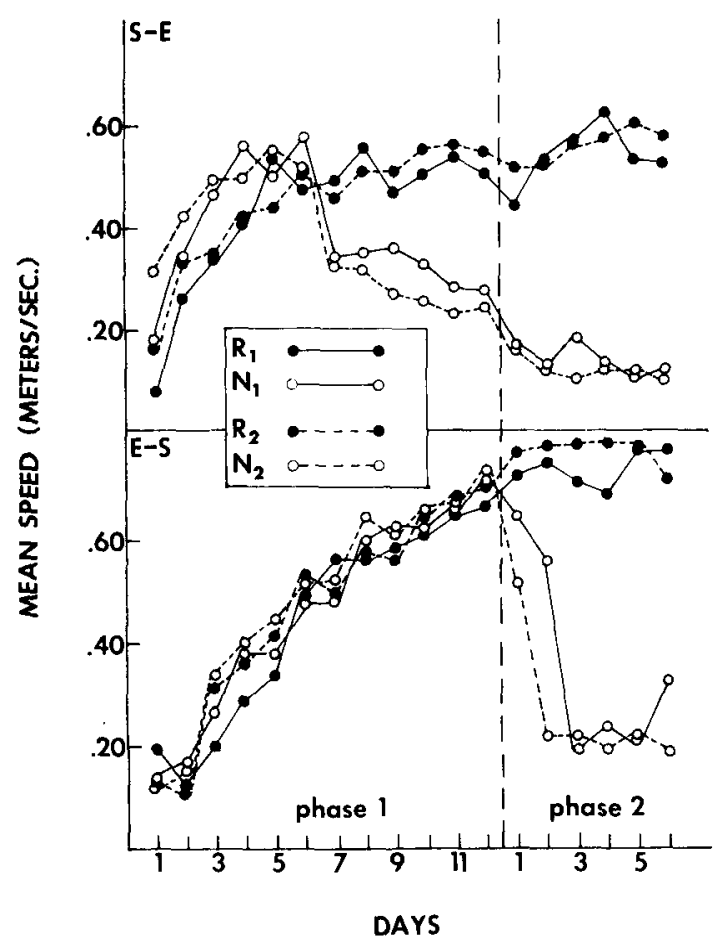

Figure 2. Mean goal speeds for Groups S-E and E-S during Phases 1 and 2 of Experiment 2.

tions of Thorazine and Elavil. When Thorazine is administered at the outset of training, performance is depressed, thus enabling subjects to attend to and respond to odor cues early in training (see Figure 1Phase 1, Group T-S). Conversely, when Elavil is administered at the outset of training, speeds are elevated and the ability to attend to odor cues severely hindered (see Figure 2-Phase 1, Group E-S).

The lack of patterned responding during Phase 1 by Group E-S (Experiment 2) might be interpreted as an indication that odors were not being produced by these subjects. Since Groups E-S and S-E were run as one large squad in Experiment 2, a consideration of the speeds of the first S-E animal (Subject 8) would appear relevant. The observation that this animal responded nondifferentially throughout Phase 1 might be taken to reflect the lack of odor production by the preceding seven subjects in Group E-S. However, the very rapid "latent-learning-like" change in N-trial performance during Phase 2 when Group E-S was shifted from Elavil to saline indicates that odors were being produced under Elavil and that the subjects had learned what the significance of such odors was. They simply failed to perform differentially under the Elavil state.

Shifting from saline-injection to drug-injection conditions (Phase 2, both experiments) failed to disrupt the strong patterned responding that had been established in Phase 1 by the control (saline) animals. 
In accord with the Prytula and Davis (1979) data, these results indicate that once odor-based patterning is well established, it appears to be relatively insensitive to a change in drug state. Shifting from the drug- to saline-injection condition (Phase 2 , both experiments) led to (1) a strengthening of patterning (i.e., greater $\mathbf{R}$ vs. $\mathbf{N}$ differences) by Group $\mathrm{T}-\mathrm{S}$ in Experiment 1, and, as mentioned, (2) the very rapid development of patterning by Group E-S in Experiment 2. Thus, it would appear reasonable to conclude that odors are produced under different drug states and that the initial use of such odors may be dependent upon the drug state of the recipient animal(s).

\section{REFERENCE NOTE}

1. Travis-Neideffer, M. N., Ludvigson, H. W., \& Moreno, R. Deprivation-state specificity of odor cues in the rat: Constraints vs. overshadowing. Paper presented at the meeting of the Southwestern Psychological Association, Houston, April 1981.

\section{REFERENCES}

Bloom, J. M., \& Phillips, J. M. Conspecific odors as discriminative stimuli in the rat. Behavioral Biology, 1973, 8, 279-283.

Davis, S. F., \& Prytula, R. E. Odor-mediated runway performance of the rat as a function of Thorazine injection. Bulletin of the Psychonomic Society, 1979, 13, 293-296.

Davis, S. F., Prytula, R. E., Harper, W. E., Tucker, H. K., LEWIS, C., \& FLOOD, L. Double-alternation runway perfor- mance as a function of inter- and intrareinforcement odor cues. Psychological Reports, 1974, 35, 787-793.

Davis, S. F., Prytula, R. E., Noble, M. J., \& Mollenhour, M. N. Motivational specificity of the signal value of odor cues. Animal Learning \& Behavior, 1976, 4, 407-410.

Davis, S. F., Whiteside, D. A., Dickson, V. A., Thomas, R. L., \& HEcK, D. G. Conditioning and retention of defensive burying as a function of Elavil and Thorazine injection. Bulletin of the Psychonomic Society, 1981, 17, 107-110.

Eslinger, P. J., \& Ludviggon, H. W. Are there constraints on learned responses to odors from rewarded and nonrewarded rats? Animal Learning \& Behavior, 1980, 8, 452-456.

Howard, G. S., \& McHose, J. H. The effects of sodium amobarbital on odor-based responding in rats. Bulletin of the Psychonomic Society, 1974, 3, 185-186.

Ludvigson, $\mathrm{H}$. W. Runway behavior of the rat as a function of intersubject reward contingencies and constancy of daily reward schedule. Psychonomic Science, 1969, 15, 41-43.

Ludvigson, H. W., \& Sytsma, D. The sweet smell of success: Apparent double-alternation in the rat. Psychonomic Science, 1967, 9, 283-284.

Mellgren, R. L., Fouts, R. S., \& Martin, J. W. Approach and escape to conspecific odors of reward and nonreward in rats. Animal Learning \& Behavior, 1973, 1, 129-132.

Morrison, R. R., \& Ludvigson, H. W. Discrimination by rats of conspecific odors of reward and nonreward. Science, 1970, 167, 904-905.

Prytula, R. E., \& Davis, S. F. Runway performance as a function of positively and negatively correlated olfactory cues. Psychological Reports, 1974, 35, 735-740.

Prytula, R. E., \& Davis, S. F. The relationship between locus of odor cues and double-alternation responding in the rat. Animal Learning \& Behavior, 1976, 4, 352-356.

(Manuscript received April 30, 1981; revision accepted for publication July 21, 1981 .) 